\title{
CONTRIBUTION TO THE METHODOLOGY OF THE DETERMINATION OF THE THERMAL CONDUCTIVITY COEFFICIENTS $\lambda$ OF MATERIALS APPLIED IN THE RAILWAY SUBBASE STRUCTURE
}

The paper focuses on the methodology of determination of thermal conductivity coefficients $\lambda$ of the construction materials of railway subbase. The determination of the thermal conductivity coefficients $\lambda$ depends on the determination of the specific heat capacity and the time interval as sub-parameters. The paper presents specialized equipment for the determination of these parameters, the stated procedures and the method of test evaluation.

The paper focuses on the presentation of the results of the experimental determination of the thermal conductivity coefficients $\lambda$ of selected construction materials (clay, track ballast, fraction $32 / 63 \mathrm{~mm}$, crushed aggregate fraction 0/32 $\mathrm{mm}$ and sandy gravel 0/32 $\mathrm{mm}$ ). In the conclusion there is the confrontation of the values of the thermal conductivity coefficients $\lambda$ stated by the experimental laboratory measurements with the values stated in TNZ 736312 and STN EN ISO 10456.

Keywords: Thermal conductivity coefficients, gravel sand layer, validation, railway structure.

\section{Introduction}

The thermotechnical properties of construction materials are the basic characteristics for the design and assessment of the railway subbase structure with regard to non-transportation load (the influence of climatic factors, mainly adverse effects of frost). From this point of view the most important characteristic is the thermal conductivity coefficient $\lambda$ of construction materials applied in the structural layers of railway subbase. As the adopted standard EN STN does not specify all the values of the thermal conductivity coefficients that are at present normally used in the subbase construction, it is necessary to specify them in the process of railway subbase dimensioning.

2. Verification of the thermal conductivity coefficients $\lambda$ of railway subbase materials

In the Slovak Republic the design and assessment of the railway subbase structure is realized in accordance with TNZ 736312 [1]. This legislative document, binding for the design and assessment of ZSR lines to transportation load (static and dynamic load) and non-transportation load (influence of climatic factors, mainly frost), contains a section dedicated to the methodology of dimensioning and assessment of the railway
Design values of the thermal conductivity coefficients $\lambda$ of railway subbase materials [1]

Table 1

\begin{tabular}{|l|c|}
\hline Material & $\begin{array}{c}\text { Thermal conductivity } \\
\text { coefficient } \lambda[\mathrm{W} /(\mathrm{m} . \mathrm{K})]\end{array}$ \\
\hline Track ballast & 2.00 \\
\hline Sandy gravel & 2.30 \\
\hline $\begin{array}{l}\text { Crushed aggregate, tailings, } \\
\text { recovered material }\end{array}$ & 2.00 \\
\hline Blast furnace slag & 0.95 \\
\hline Stabilized soil & 1.75 \\
\hline Asphalt coated aggregate & 1.15 \\
\hline Cement concrete & 2.55 \\
\hline Sandy clay & 2.20 \\
\hline Clay & 1.95 \\
\hline Silty clay & 1.70 \\
\hline Mechanically compacted aggregates & 1.80 \\
\hline Hydraulically bound aggregates & 2.20 \\
\hline Polystyrene concrete & 0.25 \\
\hline Polystyrene & 0.15 \\
\hline
\end{tabular}

\footnotetext{
* Libor Izvolt, Peter Dobes, Martin Mecar

Faculty of Civil Engineering, Department of Railway Engineering and Track Management, University of Zilina, Slovakia,

E-mail: libor.izvolt@fstav.uniza.sk
} 
subbase structure to the non-transportation load, where it states the thermal conductivity coefficients $\lambda$ of materials applied in the railway subbase structure. The stated coefficients are taken into account in the dimensioning procedure of railway subbase to adverse effects of frost - Table 1.

The Department of Railway Engineering and Track Management of the Faculty of Civil Engineering of the University of Zilina has been researching the relevancy and assessment of design of railway subbase to non-transportation load for several years. Not only because new structural materials and elements are applied into the railway subbase structure but also due to changes of some legislative documents dealing with the problem of thermotechnical proporties of construction materials and also due to recent climatic changes.

This verification is also important due to parallel modeling of the freezing process with SoilVision software for the experimental stand of the Department of Railway Engineering and Track Management of the University of Zilina. It contains a built-in subbase structure that was dimensioned for the non-transportation load according to the methodology stated in [1].

On the basis of long-term experimental measurements of the temperature regime of subbase layer that started in December 2002, conducted in the experimental stand of the Department of Railway Engineering and Track Management of the University of Zilina, it was proved that freezing of the subbase layer is not significantly influenced only by the origin and granularity, but also by the humidity of construction material built in the subbase structure. It is not known, which granulometric composition and mass moisture of the material the above stated thermal conductivity coefficients $\lambda$ were gained for. Due to this fact and also due to the verification of the freezing process flow by the mathematical analysis using SoilVision software, at the same time it is necessary to verify the thermal conductivity coefficients $\lambda$ that are used in the procedure of the design and asssessment of subbase related to adverse effects of frost according to TNZ 736312 .

Since 2008 the laboratory of the Department of Railway Engineering and Track Management has been dealing with experimental measurements to verify the thermal conductivity coefficients $\lambda$ stated in Table 1. Firstly, the testing devices that serve to determine the thermal conductivity coefficients $\lambda$ were constructed. After development of these devices and their testing, the actual verification of individual construction materials took place. It included materials that normally occur in railway subbase structures or are applied there as new materials, such as clay, track ballast, fraction $32 / 63 \mathrm{~mm}$, crushed aggregate, fraction $0 / 32 \mathrm{~mm}$ and sandy gravel $0 / 32 \mathrm{~mm}$. This paper presents the procedures of experimental measurements and the achieved results of thermal conductivity coefficients $\lambda$ of the stated construction materials in confrontation with the values stated in Table 1 .

As stressed above, to determine the thermal conductivity coefficient $\lambda$ it is necessary to develop the device for conducting the measurements of all the needed input characteristics that enter the relations for its calculation. These characteristics are primarily the time interval $t$ and the specific heat capacity $c$. For each of the above stated mass moistures three measurements were conducted, they were averaged and the result was compared to the value of the thermal conductivity coefficient $\lambda$ stated in [1].

\subsection{Determination of the thermal conductivity coefficient $\lambda$ of selected construction materials with the method of non-stationary heat flow}

As in Slovakia after cancelling STN 721105 there is not any valid standard that can be applied in the measurements, the measurement procedure was realized according to the Czech standard CSN 721105 [2]. The stated standard only considers the maximum fraction $16 \mathrm{~mm}$, so the procedure had to be partially adjusted to be suitable for fraction $0 / 32 \mathrm{~mm}$ and $32 / 63 \mathrm{~mm}$. The determination of the thermal conductivity coefficient $\lambda$ is based on the Fourier's differential equation that describes the unidirectional heat transfer in homogeneous materials by spreading. The equation can be stated as:

$$
q(x, t)=-\lambda \frac{\delta \theta_{(x, t)}}{\delta x}
$$

where:

$q(x, t)$ - heat flow density in place $\mathrm{x}$ and in time $\mathrm{t},\left(\mathrm{W} / \mathrm{m}^{2}\right)$,

$\lambda \quad$ - thermal conductivity coefficient, $[\mathrm{W} /(\mathrm{m} . \mathrm{K})]$,

$\theta_{(x, t)} \quad$ - temperature in place $\mathrm{x}$ and in time $\mathrm{t},(\mathrm{K})$.

Depending on the environment, the heat flow can be expressed using the relation:

$$
\frac{\delta q_{(x, t)}}{\delta x}=-\rho \cdot c \frac{\delta T_{(x, t)}}{\delta t}
$$

where: $\rho$ - volumetric mass, $\left(\mathrm{kg} / \mathrm{m}^{3}\right)$,

$$
\text { c - specific heat capacity, }[\mathrm{J} /(\mathrm{kg} . \mathrm{K})] \text {. }
$$

After some adjustment from the relations (1) and (2) an equation to characterize the temperature field development can be derived. This equation can be stated in the form:

$$
\frac{\delta \theta_{(x, t)}}{\delta t}=\frac{\lambda}{\rho \cdot c} \cdot \frac{\delta^{2} \theta_{(x, t)}}{\delta x^{2}}
$$

By the adjustment of the relation (3), using the method of finite elements with the boundary conditions $\theta_{0}=10^{\circ} \mathrm{C}, \theta_{\mathrm{M}}=0{ }^{\circ} \mathrm{C}$, the time interval $\mathrm{t}$ between the $10 \%$ and $50 \%$ decrease of the initial temperature difference measured on the specimen bottom is determined.

This time interval is determined from the graphic assessment of the temperature flow measurements on the specimen bottom, in the place where the temperature decrease flow is the stablest in the given interval. After the adjustment, the relation (3) is stated as:

$$
\frac{\lambda}{\rho \cdot c}=0.249 \frac{h^{2}}{t}
$$

where $\mathrm{h}$ is the specimen thickness in $\mathrm{m}$.

By the mathematical adjustment the equation (4) obtains its final form for the calculation of the thermal conductivity coefficient $\lambda$ and can be stated as: 


$$
\lambda=0.249 \frac{h^{2}}{t} \rho \cdot c
$$

In this relation two main parameters become prominent, namely the specific heat capacity $\mathrm{c}$ and the time interval $\mathrm{t}$. The procedure for their determination will be characterized in the further parts of this paper.

\subsubsection{Calorimetric test [3]}

The calorimetric test serves to determine the specific heat capacity $\mathrm{c}(\mathrm{J} /(\mathrm{kg} . \mathrm{K})$. This parameter is necessary for the indirect determination of the thermal conductivity coefficient $\lambda$. A special device demonstrated by Fig. 1 was constructed to specify it. The exact determination of the specific heat capacity c, as well the time interval $t$ is a complex technological process and plays a crucial role in achieving overall results.

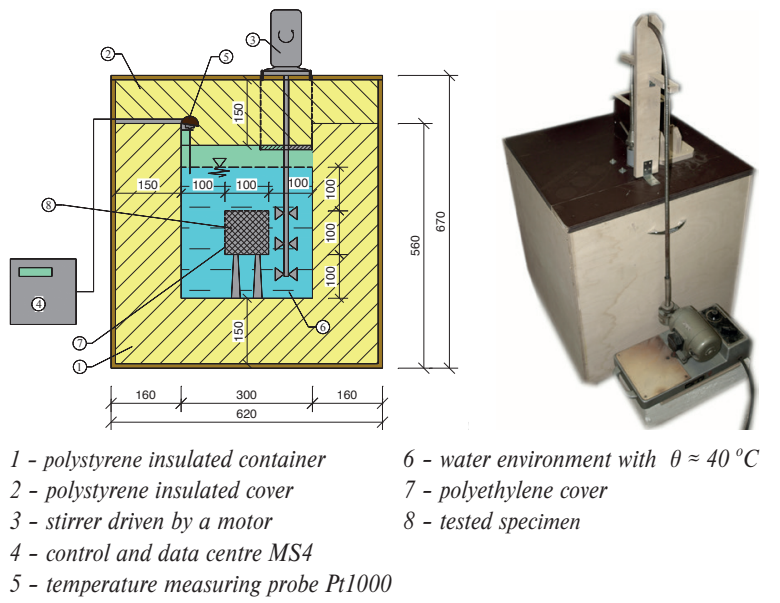

Fig. 1 Calorimeter

Calorimetric test procedure:

- preparation of the necessary parts of a calorimeter,

- mass moisture adjustment of the tested material,

- specimen collection and its placement into the polyethylene foil,

- weighing the specimen and tempering its temperature at the value $+20{ }^{\circ} \mathrm{C} \pm 2{ }^{\circ} \mathrm{C}$

(placement into the sand layer of a given temperature),

- filling the calorimeter with water of temperature $+40^{\circ} \mathrm{C} \pm 2{ }^{\circ} \mathrm{C}$ and its constant stirring

(stirrer with an electric motor),

- temperature stabilisation in the calorimeter (approx. $45 \mathrm{~min}$.),

- input of the tested specimen into the calorimeter,

- registering the specimen temperature consumption for the temperature compensation between the specimen and water (the constant temperature curve signifies the completion of collecting the heat from the water medium),

- determination of the difference between the initial and final temperature with the help of parallel lines (Fig. 2) that are the tangent curve (the use of AutoCAD),
- calculation of the specific heat capacity $\mathrm{c} 0$ of the sandy gravel specimen in a dry state according to the relation:

$$
c_{0}=\frac{m_{v} \cdot c_{v}+K}{m} \cdot \frac{\theta_{P}-\theta_{K}}{\theta_{K}-\theta}
$$

where:

$\mathrm{c}_{0} \quad$ - specific heat capacity of the dry specimen, $[\mathrm{J} /(\mathrm{kg} . \mathrm{K})]$,

$\mathrm{m}_{\mathrm{v}}$ - mass of water, $(\mathrm{kg})$,

$\mathrm{c}_{\mathrm{v}} \quad$ - specific heat capacity of water, $[\mathrm{J} /(\mathrm{kg} . \mathrm{K})]$,

$\mathrm{m}$ - mass of the tested specimen, $(\mathrm{kg})$,

$\theta_{\mathrm{P}} \quad$ - initial temperature of water, $\left({ }^{\circ} \mathrm{C}\right)$,

$\theta_{\mathrm{K}} \quad$ - final temperature of the system, $\left({ }^{\circ} \mathrm{C}\right)$,

$\theta \quad$ - specimen temperature prior to measurement, $\left({ }^{\circ} \mathrm{C}\right)$.

$\mathrm{K} \quad$ - heat capacity of calorimeter, $(\mathrm{J} / \mathrm{K})$

For the conversion of the specific heat capacity of the sandy gravel specimen from the dry to the mass moisture state the following relation is valid:

$$
c=c_{0}+\left(c_{v}-c_{0}\right) \cdot \frac{w_{m}}{100+w_{m}}
$$

where:

c - specific heat capacity of mass moisture material, [J/(kg.K)],

wm - mass moisture of specimen, $(\%)$.

The graphic record of the calorimetric test of the sandy gravel layer and the method of its evaluation is obvious from Fig. 3.

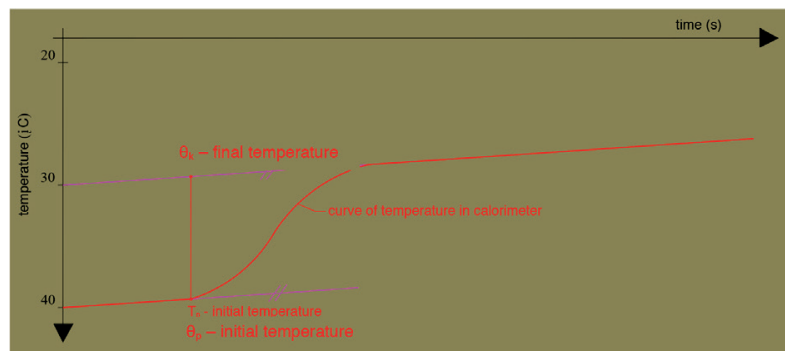

Fig. 2 Dependence of the thermal process flow on time and the method of measurement evaluation

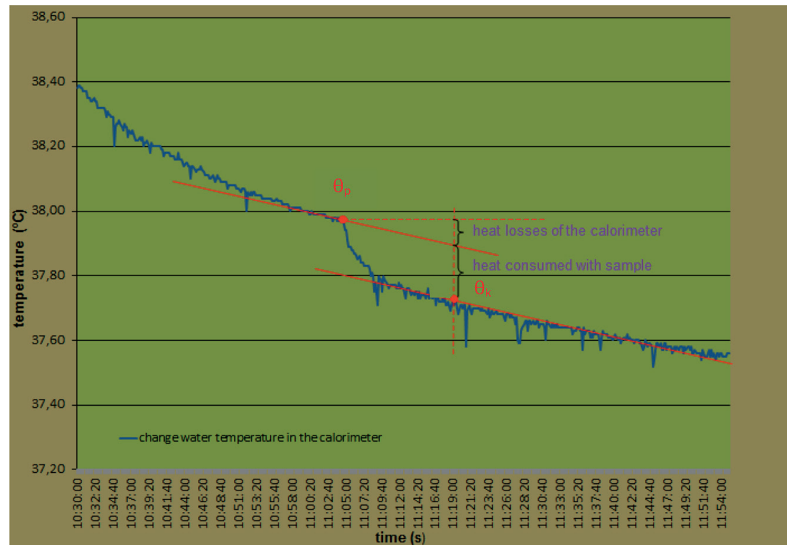

Fig. 3 Graphic record of the calorimetric test of the sandy gravel layer and the method of its evaluation 


\subsubsection{Measurement of time interval $t[3]$}

The time interval $\mathrm{t}(\mathrm{s})$ is another characteristic necessary for the indirect determination of the thermal conductivity coefficient $\lambda$. This characteristic cannot be determined via standard laboratory tests and, therefore, in this case a special device for its determination had to be invented (Fig. 4).

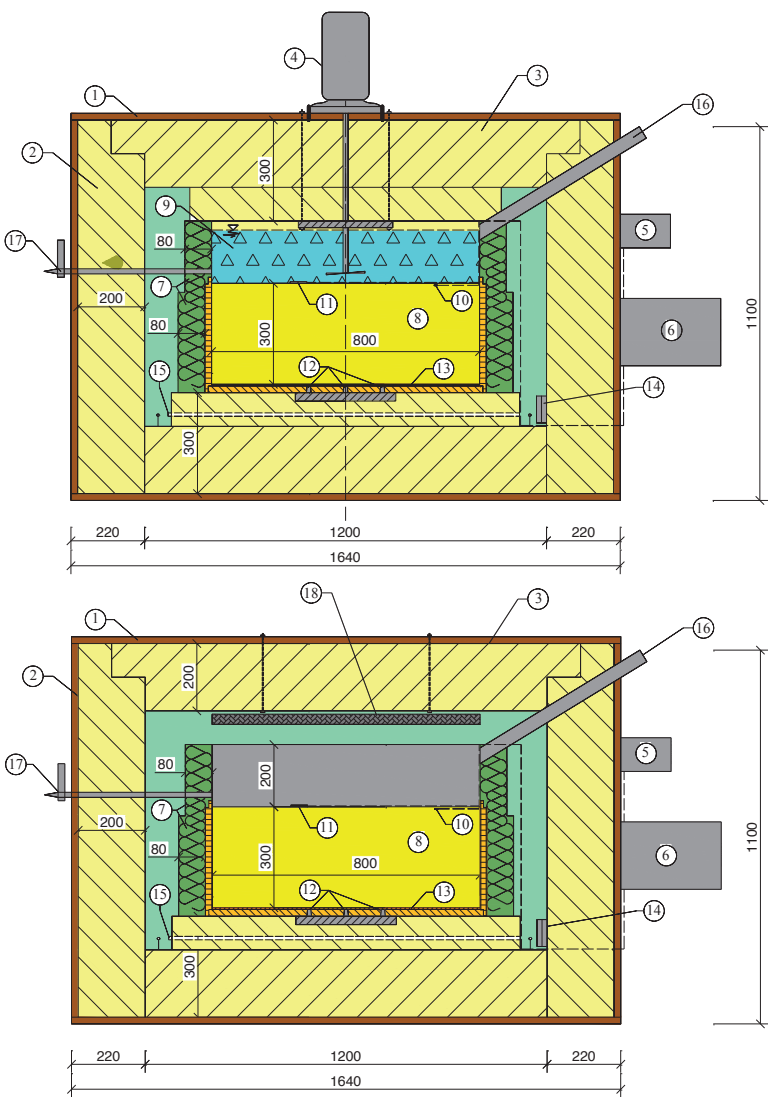

Fig. 4. Device for recording the time interval $t$

The procedure of determining the time interval $\mathrm{t}$ : - thermo-insulated chamber the specimen 12 - probes for temperature measuring on surface (PT 100)

2 - polystyrene insulated cover

3 - polystyrene insulation of the chamber

4 - stirrer driven by an electric motor

5 - power supply

6 - control and data centre MS

- thermal insulation

8 - tested specimen

9 - crushed ice of the crushed ice

10 - probe for measuring the temperature on

11 - heater element

- preparation of the device components necessary for the measurement of the time interval $t$,

- adjustment of the specimen mass moisture (drying, saturation with water),
- spreading out and compaction of the tested material in layers of $130 \mathrm{~mm}$ in the laminate container of a cylindrical shape, of diameter $800 \mathrm{~mm}$ and of height $300 \mathrm{~mm}$,

- flattening of the specimen surface with the help of standard sand,

- placement of the container to the climatic chamber with the help of lifting equipment and embedding of a temperature sensor into its upper part,

- cleaning and treatment of the bottom contact area of a stainlesssteel container (application of a vaseline layer) for the colling medium and its placement on the specimen surface,

- placement of the temperature sensor into the stainless-steel container and closing of the climatic chamber by the thermal insulation cover with a radiant panel,

- specimen heating setup to the value close to $35^{\circ} \mathrm{C}$ and its tempering to $+20^{\circ} \mathrm{C} \pm 2{ }^{\circ} \mathrm{C}$ (on the upper and bottom part of the specimen),

- exchange of radiant panel for the panel with the embedded stirrer,

- filling the stainless container with a cooling medium (water and crushed ice of the temperature $0^{\circ} \mathrm{C}$ ) with a filling pipe (approx. 401 of the mixture),

- initiation of the stirring device and addition of the mixture to the volume of approx. 651 ,

- adding the ice as necessary up to the maximum volume 751 of the mixture.

- monitoring the temperature to the moment when the temperature in the lower part of the specimen decreases by $50 \%$ compared to the temperature at the start of measurement,

- processing and evaluation of the graphic record from the measurements (Figs. 5 and 6) conducted with the help of COMET program(dependance of temperature on time),

- specimen collection for the determination of its granulometry and the test evaluation with SOILAB program,

- determination of the tested specimen mass moisture, drying the specimens in a drying room at the temperature of $105{ }^{\circ} \mathrm{C}$, for 12 hours.

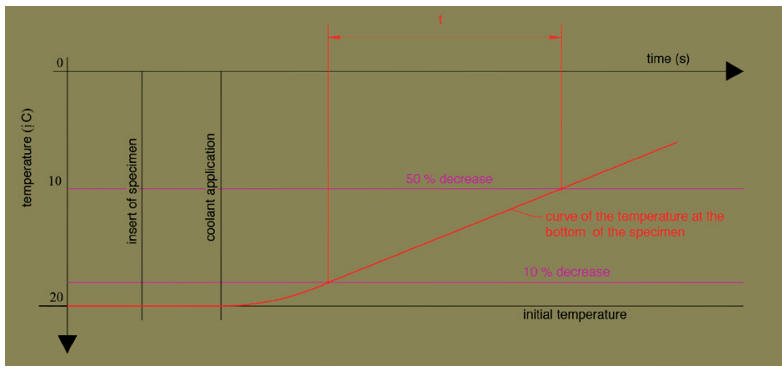

Fig. 5 Dependence of thermal process flow in the calorimeter on time and the method of measurement evaluation 13 - transfer plate

14 - probe for measuring the ambient air temperature 15 - resistance wire

16 - pipe for input of the ring for crushed ice - pipe with a vent for the draining of the cooling mixture

18 - radiant panel for heating and thermoregulation of the specimen 


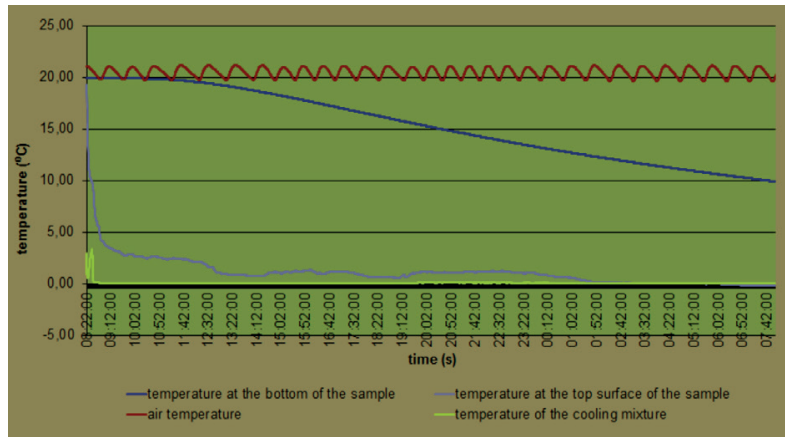

Fig. 6 Example of a graphic record of temperatures for measuring the time interval on a gravel sand specimen with $\mathrm{wm} \cong 0 \%$

\subsection{Evaluation of results of experimental measurements [3 and 4]}

As previously stressed, by conducting the experimental measurements we aim to justify the relevancy of the values of the thermal conductivity coefficients $\lambda \mathrm{W} /(\mathrm{m} . \mathrm{K})$ stated in [1] with regard to the new legislation. Moreover, in this way it is possible to obtain the values of the thermal conductivity coefficients for the materials that are at present applied into the subbase structure as new materials and are not included in the design values stated in [1]. Until now the following materials that are normally used in the subbase structure have been tested: track ballast, crushed aggregate, gravel sand and sandy clay. For each specimen of a given material a set of measurements was conducted while its evaluation was based on the correlation dependencies with determining parameters and influencing factors. Due to a high number of measurements done on the specimens, the detailed evaluation with the stated measured values is presented as a model evaluation on one specimen only, specifically for the railbed material (section 2.2.1). For all the other tested railway subbase materials only the obtained final average values of the input parameters for the calculation of the thermal conductivity coefficient as well as its final average values are stated.

\subsubsection{Determination of the thermal conductivity coefficient $\lambda$ of "new" track ballast fr. $32 / 63 \mathrm{~mm}$}

The measurement of the thermal conductivity coefficient was conducted on the railbed material collected from the manufacture (track ballast, fraction $32 / 63 \mathrm{~mm}$ ) at its natural mass moisture. The obtained results are valid for the pollution rate of the track ballast $1.86 \%$ (washed away particles) and the mass moisture of $1.17 \%$. Within the measurements this material was also tested for the pollution rate $3.08 \%$ and the mass moisture $1.31 \%$, for the sake of determination of the influence of the amount of the washed away particles on the value of the thermal conductivity coefficient $\lambda$.

\section{Determination of the specific heat capacity $c$}

The design value of the specific heat capacity of gravel sand was determined from the measurements stated in Table 2, while the given values were stated using the tested specimen that were dried in the laboratory dryer at the temperature $105^{\circ} \mathrm{C}$.

The design value of the specific heat capacity of the tested material with the pollution rate $1.86 \%$ is $\mathrm{c}=980 \mathrm{~J} /(\mathrm{kg} . \mathrm{K})$ and for the material with the pollution rate $3.08 \%$ it is $\mathrm{c}=937 \mathrm{~J} /(\mathrm{kg} . \mathrm{K})$.

Input data for the determination of the specific heat capacity $\mathrm{c}$

Table 2

\begin{tabular}{|c|c|c|c|c|c|c|}
\hline $\begin{array}{c}\text { Measurement } \\
\text { number }\end{array}$ & $\begin{array}{c}\theta \\
\left({ }^{\circ} \mathrm{C}\right)\end{array}$ & $\begin{array}{c}\theta_{p} \\
\left({ }^{\circ} \mathrm{C}\right)\end{array}$ & $\begin{array}{c}\theta_{k} \\
\left({ }^{\circ} \mathrm{C}\right)\end{array}$ & $\begin{array}{c}m_{v} \\
(\mathrm{~kg})\end{array}$ & $\begin{array}{c}m \\
(\mathrm{~kg})\end{array}$ & $\begin{array}{c}c \\
{[\mathrm{~J} /(\mathrm{kg} . \mathrm{K})]}\end{array}$ \\
\hline 1 & 11.76 & 40.76 & 40.404 & 18.09 & 0.80 & 1092 \\
\hline 2 & 17.00 & 40.29 & 40.005 & 18.09 & 0.94 & 926 \\
\hline 3 & 19.24 & 41.36 & 41.026 & 18.09 & 1.17 & 922 \\
\hline $4^{*}$ & 17.77 & 41.34 & 41.007 & 18.09 & 1.12 & 905 \\
\hline $5^{*}$ & 18.35 & 39.19 & 38.865 & 18.09 & 1.15 & 968 \\
\hline $6^{*}$ & 19.22 & 40.81 & 40.348 & 18.09 & 1.81 & 937 \\
\hline
\end{tabular}

"the measurements were realized on the material with the pollution rate $3.08 \%$

Input values for the calculation of the thermal conductivity coefficient $\lambda$

Table 3

\begin{tabular}{|c|c|c|c|c|c|}
\hline $\begin{array}{c}\text { Measurement } \\
\text { number }\end{array}$ & $\begin{array}{c}\rho \\
\left(\mathrm{kg} / \mathrm{m}^{3}\right)\end{array}$ & $\begin{array}{c}\mathrm{w}_{\mathrm{m}} \\
(\%)\end{array}$ & $\mathrm{c}[\mathrm{J} /(\mathrm{kg} \cdot \mathrm{K})]$ & $\begin{array}{c}\mathrm{t} \\
(\mathrm{s})\end{array}$ & $\begin{array}{c}\lambda \\
{[\mathrm{W} /(\mathrm{m} . \mathrm{K})]}\end{array}$ \\
\hline 1 & 1702 & 1.17 & 1047 & 67500 & 0.622 \\
\hline 2 & 1718 & 1.17 & 1047 & 67020 & 0.620 \\
\hline $3^{*}$ & 1903 & 1.31 & 980 & 60000 & 0.673 \\
\hline $4^{*}$ & 1915 & 1.31 & 980 & 60300 & 0.672 \\
\hline
\end{tabular}

*the measurements were realized on the material with the pollution rate $3.08 \%$ 
Determination of the time interval $t$ and the value of the thermal conductivity coefficient $\lambda$

The character of the tested specimens regarding their granularity required a special adjustment of the contact surface area to prevent falling of the flattening material and filling the space among the grains. Due to this reason a very thin and adjustable foil was placed under this layer to copy the surface of the aggregate grains and also to prevent the formation of a relevant thermal insulation layer.

Table 3 shows the values that directly enter the calculation of the thermal conductivity coefficient $\lambda$, including their resulting values.

The design value of the thermal conductivity coefficient $\lambda$ was obtained by the arithmetic average of the measurement results and it is $\lambda=0.621 \mathrm{~W} /(\mathrm{m} . \mathrm{K})$ for the track ballast material with the pollution rate $1.38 \%$, and $\lambda=0.673 \mathrm{~W} /(\mathrm{m} . \mathrm{K})$ for the material with the pollution rate $3.08 \%$.

\subsubsection{Determination of the thermal conductivity coefficient $\lambda$ of track ballast fr. $32 / 63 \mathrm{~mm}$ from the railway line in operation}

In real conditions of railway track operation the rail bed is contaminated by various alien material that after reaching certain amount, (i.e. level of track ballast contamination), causes changes of not only physico-mechanical, but also thermotechnical properties of this structural layer. The alien material that causes the track ballast contamination enters the railbed in several ways. These are the results of operation (falling of the transported materials from leaking wagons), maintenance (tamping the sleepers), but also the influence of climatic factors (grain disintegration due to frost).

To determine the thermotechnical properties of the railbed material contaminated in this way the specimens from two different locations that differed in the pollution rate, were tested. The specimens No. 1 and No. 2 were collected from the running track of the railway line Zilina - Kosice, from the interstationa section Zilina - Varín, specifically in the stop Teplicka n. Vahom, from the rail No. 2 (Fig. 7). The specimens No. 3 and No. 4

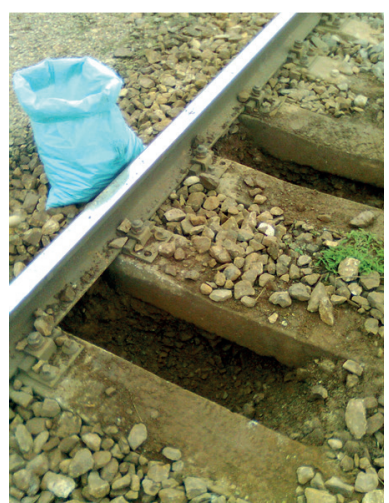

Fig. 7 Place of the collection of the specimen No.1

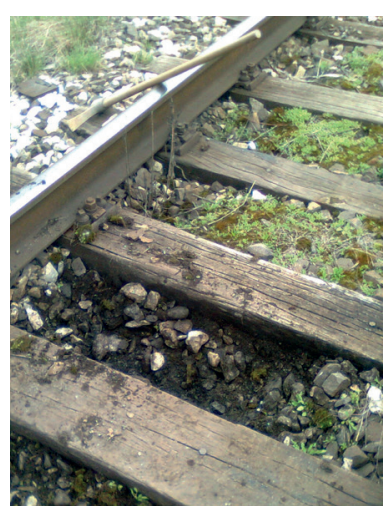

Fig. 8 Place of the collection of the specimen No.3 were collected from the identical line, specifically in the station Varin, from the loading rail No. 6 (Fig. 8). By the laboratory measurements it was found out that the specimens No. 1 and No. 2 reached the pollution rate $6.35 \%$, while the specimen No. 3 and No. $4-3.16 \%$ only, which can be considered a benefit for the purposes of the verification of the thermal conductivity coefficient $\lambda$ of the track ballast.

\section{Determination of the specific heat capacity c}

The design value of the specific heat capacity of the railbed material (track ballast, fr. $32 / 63 \mathrm{~mm}$ ) was determined for the tested specimens from the railbed of mass moisture $\mathrm{w}_{\mathrm{m}} \cong 0 \%$. The design value of the specific heat capacity of the material of the specimens No.1 and No.2 was determined as an average value from the results of 3 measurements and is stated as $\mathrm{c}=1010 \mathrm{~J} /(\mathrm{kg} \cdot \mathrm{K})$. For the material of the specimens No. 3 and No. 4 this value was determined from 3 measurements and can be stated as $\mathrm{c}=983 \mathrm{~J} /(\mathrm{kg} . \mathrm{K})$.

Determination of the time interval $t$ and the value of the thermal conductivity coefficient $\lambda$

The measurement was conducted at the natural mass moisture of the tested material (specimens No. 1 and No. 2 for $w m=3.98 \%$ and specimens No. 3 and No. 4 for wm $=2.56 \%$ ). With regard to these mass moistures the specific heat capacity was recalculated to the value $\mathrm{c}=1138 \mathrm{~J} /(\mathrm{kg} . \mathrm{K})$ for the specimens No. 1 and No. 2 and $\mathrm{c}=981 \mathrm{~J} /(\mathrm{kg} . \mathrm{K})$ for the specimens No. 3 and No. 4. For the given mass moistures the time interval acquired the value $\mathrm{t}=50950 \mathrm{~s}$, and $52450 \mathrm{~s}$ for the specimens No. 1 and No. 2, respectively, and $t=63260 \mathrm{~s}$, and $63700 \mathrm{~s}$ for the specimens No. 3 and No. 4, respectively. On the basis of the stated values of the partial parameters, the design value of the thermal conductivity coefficient $\lambda$ for the material of the specimens No. 1 and No. 2, was obtained as an average value from 2 measurements $-\lambda=0.991$ $\mathrm{W} /(\mathrm{m} . \mathrm{K})$ and for the material of the specimens No. 3 and No. 4 this value is also obtained as an average from 2 measurements $-\lambda$ $=0.750 \mathrm{~W} /(\mathrm{m} \cdot \mathrm{K})$.

\subsubsection{Determination of the thermal conductivity coefficient $\lambda$ of crushed aggregate fr. $0 / 32 \mathrm{~mm}$ and fr. $0 / 63 \mathrm{~mm}$}

With regard to the fact that in both cases the material was of the same mineralogical composition (melaphyr) and the materials only differed in granularity (and slightly different bulk density), the results of the testing mesurements are stated as a whole. The measurements of the time interval $t$ were conducted at different mass moisture conditions $\left(\mathrm{w}_{\mathrm{m}}=2.41 \%-4.68 \%\right)$, while the specific heat capacity $\mathrm{c}$ was determined for dry material $\left(\mathrm{w}_{\mathrm{m}} \cong 0 \%\right)$.

\section{Determination of the specific heat capacity $\mathrm{c}$}

The design value of the specific heat capacity of the crushed aggregate, fr. $0 / 32 \mathrm{~mm}$ and fr. $0 / 63 \mathrm{~mm}$ was stated for the tested specimens of mass moisture $\mathrm{wm} \cong 0 \%$. By the arithmetic average from 3 measured results the design value of the specific heat 
capacity $\mathrm{c}=1115 \mathrm{~J} /(\mathrm{kg} \cdot \mathrm{K})$ was stated. Due to the identical mineralogical composition this value can be considered for the fraction $0 / 32 \mathrm{~mm}$ as well as fraction $0 / 63 \mathrm{~mm}$.

\section{Determination of the time interval $t$ and the value of the therma} conductivity coefficient $\lambda$

The measurement was conducted at different mass moisture of the tested material $\left(\mathrm{w}_{\mathrm{m}}=2.41 \%-4.68 \%\right)$. On the basis of the given mass moistures the specific heat capacity was recalculated for the values in the interval $\mathrm{c}=1190 \mathrm{~J} /(\mathrm{kg} . \mathrm{K})$ to $1262 \mathrm{~J} /(\mathrm{kg} . \mathrm{K})$ for the crushed aggregate, fraction $0 / 32 \mathrm{~mm}$ and $\mathrm{c}=1115 \mathrm{~J} /$ (kg.K) to $1260 \mathrm{~J} /(\mathrm{kg} . \mathrm{K})$ for fraction $0 / 63 \mathrm{~mm}$. The values of the time interval $\mathrm{t}$ of the respective mass moisture varied from $\mathrm{t}=43425 \mathrm{~s}$ to $61380 \mathrm{~s}$ for fraction $0 / 32 \mathrm{~mm}$ ( 2 higher values occurred due to the defective contact on the interface specimen/ container and as a result of spill of the cooling medium) and $\mathrm{t}=44790 \mathrm{~s}$ to $88500 \mathrm{~s}$ for fraction $0 / 63 \mathrm{~mm}$. On the basis of the values of the partial parameters from 7 measurements for fraction $0 / 32 \mathrm{~mm}$ the design value of the thermal conductivity coefficient $\lambda=1.159 \mathrm{~W} /(\mathrm{m} . \mathrm{K})$ and for fraction $0 / 63 \mathrm{~mm}$ its value is $\lambda=1.038 \mathrm{~W} /(\mathrm{m} . \mathrm{K})$, which was acquired as an average from 9 measurements.

With the help of the obtained data it is then possible to express the average dependance of the thermal conductivity coefficient $\lambda$ on the mass moisture $w$ of the tested materials - Fig. 9.

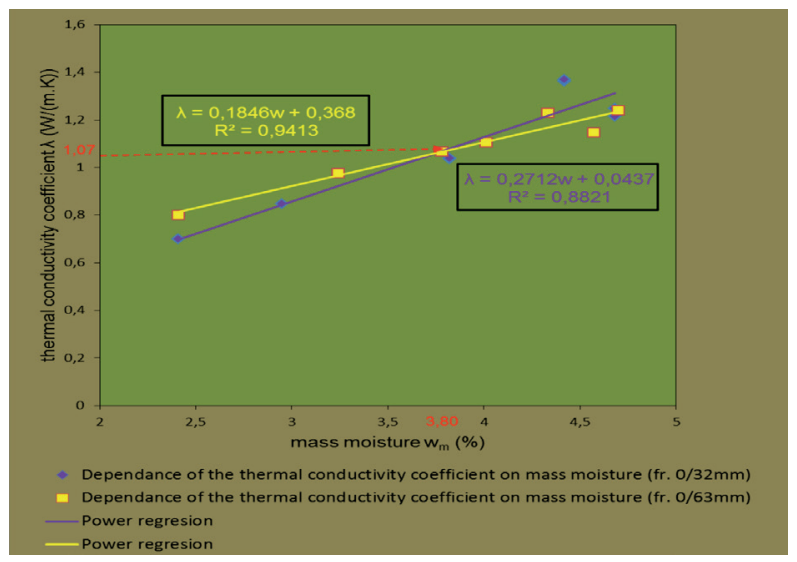

Fig. 9 Dependence of the thermal conductivity coefficient $\lambda$ on mass moisture for crushed aggregate, fraction $0 / 32 \mathrm{~mm}$ and $0 / 63 \mathrm{~mm}$

Figure 9 highlights the value of the thermal conductivity coefficient $\lambda=1.07 \mathrm{~W} /(\mathrm{m} . \mathrm{K})$ for both fractions, for the material mass moisture $\mathrm{w}_{\mathrm{m}}=3.80 \%$, which is in this case considered a natural mass moisture.

\subsubsection{Determination of the thermal conductivity coefficient $\lambda$ of sandy gravel fr. $0 / 32 \mathrm{~mm}$}

At present the sandy gravel, fr. $0 / 32 \mathrm{~mm}$ is not normally applied in the subbase layer of the railway line structure, but the design nomograms stated in [1] were specifically made for this material. Due to the necessity of comparing the results acquired by the above stated methodology and verifying the reliability of the testing devices, this was really important. As it was necessary to revise the design nomograms for the materials of the subbase layer - crushed aggregate fr. $0 / 32 \mathrm{~mm}$ and $0 / 63 \mathrm{~mm}$, it was also necessary to verify the thermal conductivity coefficient $\lambda$ for the sandy gravel, too. The measurements of the time interval $t$ were conducted at 3 different mass moistures ( $w m=0 \%, 2.46 \%$ a $4.87 \%$ ), while the specific heat capacity c was stated for the dry material $\left(\mathrm{w}_{\mathrm{m}} \cong 0 \%\right)$.

\section{Determination of the specific heat capacity $c$}

The design value of the specific heat capacity of sandy gravel fr. $0 / 32 \mathrm{~mm}$ was stated for the tested specimens of mass moisture $\mathrm{w}_{\mathrm{m}} \cong 0 \%$. By the arithmetic average from 6 measured results the design value of the specific heat capacity was determined as $\mathrm{c}=$ $854 \mathrm{~J} /(\mathrm{kg} . \mathrm{K})$.

Determination of the time interval $t$ and the value of the thermal conductivity coefficient $\lambda$

The measurement was conducted for 3 different mass moistures, specifically wm $=0 \%, 2.46 \%$ and $4.87 \%$. With regard to these mass moistures, the specific heat capacity was recalculated to the values $\mathrm{c}=854 \mathrm{~J} /(\mathrm{kg} . \mathrm{K}), 934 \mathrm{~J} /(\mathrm{kg} . \mathrm{K})$ and $1009 \mathrm{~J} /(\mathrm{kg} . \mathrm{K})$. The values of the time interval $\mathrm{t}$ of the respective mass moistures ranged in the interval $\mathrm{t}=56430 \mathrm{~s}$ to $60840 \mathrm{~s}$ for dry material, $\mathrm{t}=21240 \mathrm{~s}$ to $21840 \mathrm{~s}$ for the mass moisture $\mathrm{wm}=2.46 \%$ and $\mathrm{t}=22920 \mathrm{~s}$ to $23550 \mathrm{~s}$ for $\mathrm{wm}=4.87 \%$. From the measured values it becomes obvious that the mass moisture wm considerably influences the values of the thermal conductivity coefficient $\lambda$, and that is why it is not possible to determine the average values by the arithmetic average from all the measurements, but it has to be stated for the individual mass moistures of the tested material. On the basis of the values of the partial parameters, the design value of the thermal conductivity coefficient for sandy gravel, fraction $0 / 32 \mathrm{~mm}$ was stated as $\lambda=0.753 \mathrm{~W} /(\mathrm{m} . \mathrm{K})$ for dry material, $\lambda=2.074 \mathrm{~W} /(\mathrm{m} . \mathrm{K})$ for material of mass moisture $\mathrm{w}_{\mathrm{m}}=2.46 \%$ and $\lambda=2.362 \mathrm{~W} /(\mathrm{m} . \mathrm{K})$ for material of mass moisture $\mathrm{w}_{\mathrm{m}}=4.87 \%$. The values of all the three thermal conductivity coefficients $\lambda$

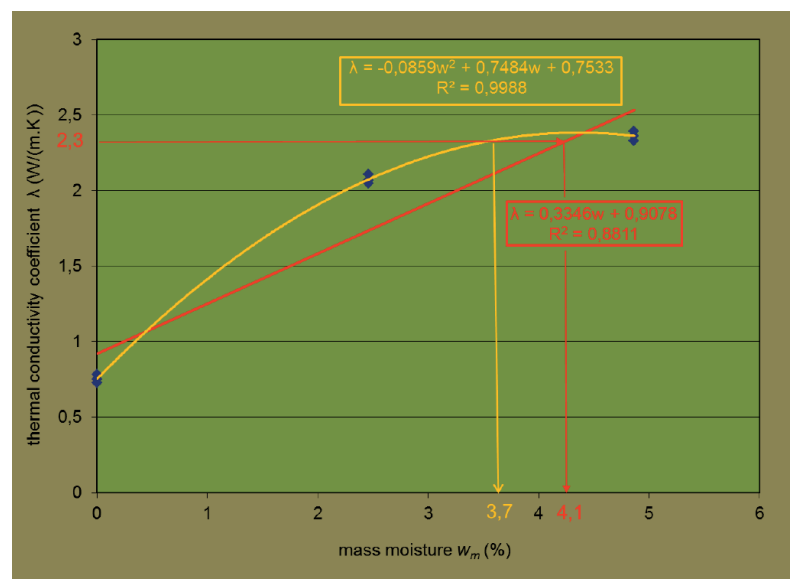

Fig. 10 Dependence of the thermal conductivity coefficient $\lambda$ of a sandy gravel layer on mass moisture wm 
were always acquired as average values of 3 measurements. The influence of humidity on the thermal conductivity coefficient $\lambda$ of gravel sand, leading from the measured values is shown by Fig. 10. This evaluation clearly shows that the values of the thermal conductivity coefficient $\lambda$ grow with increasing mass moisture and that is why the value of the thermal conductivity coefficient stated in Table 1 is valid for sandy gravel of mass moisture $\mathrm{wm}=$ approx. 3,7 (resp. 4,1)\%.

\subsubsection{Determination of the thermal conductivity coefficient $\lambda$ of sandy clay}

To detemine the thermal conductivity coefficient $\lambda$ of sandy clay we used the material gained from the railway subbase earthwork - of the testing stand of the Department of Railway Engineering and Track Management.

\section{Determination of the specific heat capacity $c$}

The tested specimens, as previously, were dried and subsequently the testing measurement was conducted. The design value of the specific heat capacity of sandy clay was acquired as an average value of 4 measurements and it is $\mathrm{c}=1034 \mathrm{~J} /(\mathrm{kg} \cdot \mathrm{K})$.

Determination of the time interval $t$ and the value of the thermal conductivity coefficient $\lambda$

The measurement was conducted for 2 different mass moistures, specifically: $\mathrm{wm}=17.46 \%$ and $\mathrm{wm}=15.67 \%$. On the basis of different mass moistures that specific heat capacity was recalculated to the values $\mathrm{c}=1582 \mathrm{~J} /(\mathrm{kg} . \mathrm{K})$ and $1585 \mathrm{~J} /(\mathrm{kg} . \mathrm{K})$. The values of the time interval $t$ of the respective humidities ranged in the interval $t=50930 \mathrm{~s}$ to $52470 \mathrm{~s}$. On the basis of values of partial parameters for sandy clay the design value of the thermal conductivity coefficient $\lambda$ was determined as an average of 2 measurements and can be stated as $\lambda=1.211 \mathrm{~W} /(\mathrm{m} . \mathrm{K})$ for mass moisture $\mathrm{wm}=15.67 \%$ and as the value of $\lambda=1.504 \mathrm{~W} /$ (m.K) for mass moisture $\mathrm{wm}=17.46 \%$.

\subsubsection{Determination of the thermal conductivity coefficient $\lambda$ of sand}

To detemine the thermal conductivity coefficient $\lambda$ of sand we used the material gained from landfill sand.

\section{Determination of the specific heat capacity $c$}

The tested specimens, as previously, were dried and subsequently the testing measurement was conducted. The design value of the specific heat capacity of sand was acquired as an average value of 2 measurements and it is $\mathrm{c}=1174 \mathrm{~J} /(\mathrm{kg} . \mathrm{K})$.

Determination of the time interval $t$ and the value of the thermal conductivity coefficient $\lambda$

The measurement was conducted for one mass moisture, specifically: $\mathrm{wm}=3.73 \%$. On the basis of this mass moisture that specific heat capacity was recalculated to the value $\mathrm{c}=1287 \mathrm{~J} /(\mathrm{kg} \cdot \mathrm{K})$. The values of the time interval $\mathrm{t}$ of the respective mass moisture ranged in the interval $t=29580 \mathrm{~s}$ to 29700 s. On the basis of values of partial parameters for sand the design value of the thermal conductivity coefficient $\lambda$ was determined as an average of 2 measurements and can be stated as $\lambda=1.836 \mathrm{~W} /(\mathrm{m} . \mathrm{K})$ for mass moisture $\mathrm{wm}=3.73 \%$.

\section{Conclusion}

The thermal conductivity coefficient $\lambda$ is a physical characteristic that indicates the substance ability to conduct heat, thus using it we can consider the material resistance against the heat flow. The design values of the thermal conductivity coefficient of the materials of railway subbase structure stated in Table 1 [1] are considerably different from the values measured with the help of the adjusted methodology of the non-stationary heat flow. Table 4 shows the stated standard (design) as well as measured values of $\lambda$ (valid for the natural mass moisture of the material) for the tested railway subbase materials.

Measured and standard values of $\lambda$

Table 4

\begin{tabular}{|l|c|c|}
\hline \multicolumn{1}{|c|}{ Material } & $\begin{array}{c}\lambda(\mathrm{TNZ} 73 \text { 6312) } \\
{[\mathrm{W} /(\mathrm{m} . \mathrm{K})]}\end{array}$ & $\begin{array}{c}\text { coefficient } \lambda \\
\text { (measured) } \\
{[\mathrm{W} /(\mathrm{m} . \mathrm{K})]}\end{array}$ \\
\hline $\begin{array}{l}\text { Track ballast } 32 / 63 \mathrm{~mm} \\
\text { "clean" }\end{array}$ & 2.00 & $0.62-0.67$ \\
\hline Track ballast contaminated & - & $0.75-0.99$ \\
\hline Crushed aggregate $0 / 32 \mathrm{~mm}$ & 2.00 & $0.70-1.37$ \\
\hline Crushed aggregate $0 / 63 \mathrm{~mm}$ & 2.00 & $0.64-1.28$ \\
\hline Sandy gravel $0 / 32 \mathrm{~mm}$ & 2.30 & $0.75-2.36$ \\
\hline Sand & - & 1.84 \\
\hline Sandy clay & 1.70 & $1.21-1.50$ \\
\hline
\end{tabular}

Due to the verification of results of the experimental determination of the thermal conductivity coefficients $\lambda$ of the selected railway subbase materials these were confronted. The independent and at the same time relevant source is at present the valid standard STN EN ISO 10456 [5]. In this normative document, with regard to the specific properties of materials applied in the subbase structure, it is possible to conduct this verification of the thermal conductivity coefficient $\lambda$ for clay and silica sand, fraction $0 / 2 \mathrm{~mm}$. These soils also normally occur in the railway subbase structure. The comparison of the measured and standard values is done in Table 5 , while both materials were tested at their natural mass moisture wm.

Measured and standard values of $\lambda$

Table 5

\begin{tabular}{|l|c|c|}
\hline \multicolumn{1}{|c|}{ Material } & $\begin{array}{c}\lambda \text { (STN EN ISO 10 456) } \\
{[\mathrm{W} /(\mathrm{m} . \mathrm{K})]}\end{array}$ & $\begin{array}{c}\lambda \text { (measured) } \\
{[\mathrm{W} /(\mathrm{m} . \mathrm{K})]}\end{array}$ \\
\hline Clay, loam & 1.50 & $1.21-1.50$ \\
\hline Sand & 2.00 & 1.84 \\
\hline
\end{tabular}


Table 5 clearly shows that the value of the thermal conductivity coefficient $\lambda$ for silty clay and sand corresponds roughly with standard values. It can thus be assumed that the measurement methodology is correct and the results are probably reliable. It is then possible to conduct the testing of other construction materials stated in Table 1 or the ones that are at present applied in the railway subbase structure [6] and their thermal conductivity coefficient values are unknown and if applied it is not possible to conduct the structural assessment for the adverse effects of frost according to the design methodology stated in [1].

\section{Acknowledgement}

The presented results are the results of solving the VEGA grant project 1/0756/12 "Experimental monitoring and mathematical modelling of thermal regime of railway subgrade structure", which allows the realization of experimental measurements and consequently obtaining the relevant results that are presented in this paper.

\section{References}

[1] TNZ 736312 Design of Structural Layers of Railway Subbase (in Slovak), GR ZSR, August 2005

[2] CSN 721105 Determination of Thermal Conductivity Coefficient with the Method of Non-stationary Heat Flow (in Slovak), 1990

[3] KUPCULIAK, P.: Design and Assessment of Railway Subbase from the Point of View of Load by Climatic Factors (in Slovak), Dissertation thesis, Zilinska univerzita, SvF, KZSaTH, Zilina, 2011

[4] DOBES, P.: Optimization of Selected Conditions of the Railway Subbase Structure Design with Regard to Non-transportation Load (in Slovak), Diploma thesis, University of Zilina Faculty of Civil Engineering, Department of Railway Engineering and Track Management, 2012.

[5] STN EN ISO 10456 Construction Materials and Products. Hygrothermal Properties. Tabulated Design (Calculated) Values and Procedures for the Determination of Declared and Design Values of Thermal Quantities, (ISO 10456: 2007).

[6] DURICA, P., VERTAL, M.: Verification of the Water Transport Parameter - Moisture Storage Function of Autoclaved Aerated Concrete - Approximately Calculated from a Small Set of Measured Characteristic Values, Communications - Scientific Letters of the University of Zilina, No. 4, 2011, pp. 92-97. 